\title{
Serum lipophilic antioxidants levels are associated with leucocyte telomere length among US adults
}

\author{
Mohsen Mazidi ${ }^{*}$, Andre Pascal Kengne ${ }^{2}$, L. J. Cheskin ${ }^{3,4}$ and Maciej Banach ${ }^{5,6,7}$
}

\begin{abstract}
Background: To examine the association between serum concentrations of antioxidant and telomere length (TL) in U.S adults.

Methods: Participants of the National Health and Nutrition Examination Survey (NHANES) with data available on TL measures from 2001 to 2002 were included. Serum lipophilic antioxidants level was measured using high performance liquid chromatography with photodiode array detection. We used analysis of co-variance and multivariable-adjusted linear regression models, accounting for the survey design and sample weights.

Results: Of the 5992 eligible participants, $47.5 \%(n=2844)$ were men. The mean age was 46.9 years overall, 47.2 years in men and 46.6 in women $(p=0.071)$. In age, sex, race, education, marital status, adiposity, smoking, C-reactive protein adjusted linear regressions, antioxidant, serum a-carotene, trans- $\beta$-carotene, cis- $\beta$-carotene, $\beta$-cryptoxanthin and combined Lutein/zeaxanthin were positively and significantly associated with TL (all $p<0.001$ ).

Conclusions: Our findings support a possible positive association between serum concentrations of lipophylic antioxidant and TL. The implications of this association deserve further investigation.
\end{abstract}

Keywords: Telomere length, Antioxidant, National health and nutrition examination survey

\section{Background}

Telomeres are repetitive DNA sequences bound by specialized interacting proteins that are found at the ends of chromosomes [1]. Telomeres serve multiple functions: They maintain chromosome stability and integrity, regulate cellular proliferation, and prevent chromosome end fusions [2]. Telomeres are progressively eroded due to successive rounds of cell division, and due to such processes as oxidative stress [3]. Endogenous (i.e., genetics, inflammation, and DNA damage) and environmental (i.e., smoking, alcohol, and life stress) factors are involved in telomere maintenance and regulation [4-7]. Therefore, variation in telomere length (TL) between individuals of equal chronological age, could be due to

\footnotetext{
* Correspondence: moshen@genetics.ac.cn; mazidi@chalmers.se 1 Department of Biology and Biological Engineering, Food and Nutrition Science, Chalmers University of Technology, SE-412 96 Gothenburg, Sweden Full list of author information is available at the end of the article
}

differences in both genetic factors and environmental determinants (including adiposity) [4-7].

Shorter leukocyte TL is associated with aging $[8,9]$ and age-related diseases, such as cardiac disease [10, 11], diabetes [12, 13], hypertension [12, 14, 15], cancer [16], as well as with increased mortality [17]. Shorter LT is associated with greater oxidative stress $[18,19]$. In this regard, evidence from previous in vitro, in vivo [19], and clinical studies $[10,12,20]$ suggests that an imbalance between free oxygen radicals and antioxidant concentration in the cellular environment contributes to telomere attrition. Epidemiological studies report an inverse association between dietary micronutrients and oxidative stress [21], which suggests that dietary micronutrients may exert protective effects on TL through anti-oxidative effects. Antioxidants have attracted attention as an efficient tool in counteracting oxidative stress [22]. A limited number of studies have investigated the association between self-reported dietary antioxidants and TL [23, 24], and only a handful of studies have evaluated the relationship

(C) The Author(s). 2018 Open Access This article is distributed under the terms of the Creative Commons Attribution 4.0 International License (http://creativecommons.org/licenses/by/4.0/), which permits unrestricted use, distribution, and 
between TL and objectively measured serum levels of antioxidants; with however, inconsistent findings. A study examined the association between the plasma levels of antioxidative micronutrients and the leukocyte telomere length in 786 elderly adults, who had participated in the Austrian Stroke Prevention Study and reported a significantly protective effect of combined lutein/zeaxanthin on the telomere length [25]. There is still insufficient evidence regarding the link between serum antioxidant and TL in subjects.

The aim of this study was to investigate the relationship between serum antioxidant levels with TL among US adults. We have hypothesized that subjects with higher level of the anti-oxidants have longer length of telomere.

\section{Methods}

\section{Population}

The National Health and Nutrition Examination Surveys (NHANES) are ongoing, repeated cross-sectional surveys conducted by the US National Center for Health Statistics (NCHS). NHANES uses a multistage probability sampling strategy, which oversamples certain subgroups of the population, including blacks, Mexican-Americans, and those of lower socioeconomic status. The NCHS Research Ethics Review Board approved the NHANES protocol and consent was obtained from all participants. About 5000 subjects participate in NHANES each year, and the data are reported in 2-year cycles available for public use. Data collection on demographic, dietary, and behavioural information occurs through home interview-administered questionnaires, while anthropometric and biomarker data are collected by trained staff using mobile exam units. The interviews consist of questions on socio-demographic characteristics (age, gender, education, race/origin, and health insurance) and questions on previously diagnosed medical conditions. More details on the NHANES protocol is available elsewhere [26]. Details on the measurement of C-reactive protein (CRP) concentrations are available elsewhere [27]. This study was based on analysis of data from the 2001-2002 NHANES cycle. Subject less than 18 years, pregnant and lactating were excluded.

For the assessment of height and weight during the physical examination, participants were dressed in underwear, disposable paper gowns and foam slippers. A digital scale was used to measure weight to the nearest $100 \mathrm{~g}$, a fixed stadiometer was used to measure height to the nearest millimetre. Body mass index (BMI) was calculated as weight in kilograms divided by the square of height in metres [27]. Smoking status was self-reported and participants classified as current smoker or not.

\section{Leucocyte telomere measurements}

Aliquots of purified DNA, isolated from whole blood using the Puregene (D-50 K) kit protocol (Gentra Systems,
Inc., Minneapolis, Minnesota), were obtained from participants. The leukocyte TL assay was performed using the quantitative polymerase chain reaction method to measure TL relative to standard reference DNA (also known as the [telomere-to-single-copy gene ratio (T/S) ratio) [28]. Of note, this method provides an average TL from leukocytes (92 telomeres for humans). It does not have the capabilities to detect specific individual TL. Laboratory personnel were blinded to all other study measurements. The Centers for Diseases Control (CDC) conducted a quality control review before linking the TL data to the NHANES data files. The CDC Institutional Review Board granted human subject approval for this study [29].

\section{Antioxidants measurements}

A blood specimen was drawn from the participant's antecubital vein by a trained phlebotomist. Serum concentrations of retinol, $\alpha$ and $\gamma$-tocopherol, two retinyl esters, and six carotenoids ( $\alpha$-carotene, trans- $\beta$-carotene, cis $\beta$-carotene, $\beta$-cryptoxanthin, combined lutein/zeaxanthin, and trans-lycopene) were measured using high performance liquid chromatography with photodiode array detection [26]. Serum $\beta$-carotene concentrations predominantly reflect trans $\beta$-carotene, which was present in substantially higher concentrations than cis $\beta$-carotene. The $\mathrm{CVs}$ for these micronutrients were $1.9-5.7 \%$ for retinol, $1.8-3.9 \%$ for $\alpha$-tocopherol, $1.9-6.2 \%$ for $\gamma$-tocopherol, $4.2-18.3 \%$ for $\alpha$-carotene, $3.5-6.6 \%$ for trans $\beta$-carotene, $7.5-65 \%$ for cis $\beta$-carotene, $3.0-7.1 \%$ for $\beta$-cryptoxanthin, $5.5-13.4 \%$ for lutein + zeaxanthin, and $3.7-13.1 \%$ for lycopene [26].

\section{Statistical analyses}

We conducted analyses in accordance with CDC guidelines for analysis of complex NHANES data, accounting for the masked variance and using the proposed weighting methodology [30]. We have calculated adjusted (age, gender and sex) mean of the serum anti-oxidant level across the TL quarters by analysis of co-variance (ANCOVA). To determine any association between antioxidants and TL, we used both crude and multivariable-adjusted (age and sex and race and education and marital status and BMI and smoking and CRP) linear regression models. All tests were two sided, and $p<0.05$ was the level of significance. Data were analysed using SPSS complex sample module version 22.0 (IBM Corp, Armonk, NY). Sample weights were applied to account for unequal probabilities of selection, nonresponse bias, and oversampling.

\section{Results}

Of the 5992 eligible participants, $47.5 \%$ were men. The mean age was 46.9 years overall, 47.2 years in men and 46.6 in women $(p=0.071)$. With regard to education, $45.5 \%$ had completed more than high school, $23.4 \%$ had 
completed high school, while $30.8 \%$ had completed less than high school. Whites (non-Hispanic) represented 50.6\% of the participants, blacks $19.8 \%$ and Mexican-Americans $21.7 \%$. With regard to marital status, $51.4 \%$ were married, $10.2 \%$ were widowed and $7.6 \%$ divorced.

Table 1 shows the sex-age-adjusted mean of serum antioxidant levels across quartiles of TL. Adjusted mean of $\alpha$-carotene, trans- $\beta$-carotene, cis- $\beta$-carotene, $\beta$-cryptoxanthin, combined lutein/zeaxanthin, trans-lycopene, and retinol levels increased as the length of telomere increased (all $p<0.001$ ). Moreover there was an inverse association between $\gamma$-tocopherol and TL in crude model, but after adjustment for potential confounders (age and sex and race and education and marital status and BMI and smoking and CRP) the association between $\gamma$-tocopherol and TL was no longer significant. In multiple linear regressions, $\alpha$-carotene, trans- $\beta$-carotene, cis- $\beta$-carotene, $\beta$-cryptoxanthin, and combined lutein/zeaxanthin remained positively associated with TL (all $p<0.001$ ) (Table 2 ).

\section{Discussion}

We investigated the association between serum antioxidants and TL among US adults. We have found a positive association between serum levels of $\alpha$-carotene, trans- $\beta$-carotene, cis- $\beta$-carotene, $\beta$-cryptoxanthin and combined lutein/zeaxanthin with TL.

Our findings were in line with other studies that have suggested a positive association with dietary and supplemental $\alpha$-tocopherol intake [23-25, 31]. Consistent with our findings, two previous studies observed longer $\mathrm{TL}$ in participants with higher self-reported dietary $\beta$-carotene intake $[23-25,31]$. However, for $\gamma$-tocopherol, our data suggested no association, which is in line with the previous study among 786 Austrian adults [23-25, 31].

The performance of vitamin $\mathrm{A}$ and its pro-vitamin (e.g. $\beta$ and $\alpha$-carotene) has rarely been evaluated in relation to TL. Vitamin A has widespread physiologic roles, including in immune function, vision, reproduction, and cell communication. Among the plausible mechanisms by which vitamin A and its pro-vitamin could influence $\mathrm{TL}$ are its roles in immune function, inflammation, and the regulation of gene expression and epigenetic modifications [32, 33]. Two previous studies assessed the associations between serum vitamin A and TL $[24,25]$. We observed a significant positive association between TL with serum $\beta$ and $\alpha$-carotene. This is consistent with the previously reported positive association between dietary intake of vitamin A and TL in a study of 2284 women [24]. Conversely, plasma vitamin A concentrations were not associated with LTL in a study of 786 adults [25]. Carotenoids are particularly promising antioxidants, because they are capable of exerting antioxidant protection by scavenging singlet molecular oxygen and peroxyl radicals [34]. Several human studies have supported carotenoid protection against oxidation and oxidative stress-induced, age-related conditions [34]. We hypothesized that protective role of vitamin A and its procures could be at least partially related to its antioxidant activity.

Also consistent with our findings, the Austrian Stroke Prevention Study (ASPS) investigated the association of longer TL with higher plasma lutein, zeaxanthin, and vitamin $\mathrm{C}$ concentrations [25]. Findings of this study indicated that higher lutein and zeaxanthin concentrations in serum were related to longer $\mathrm{TL}$, though they found

Table 1 Age and sex adjusted mean of serum antioxidant across quartiles of telomere length

\begin{tabular}{|c|c|c|c|c|c|}
\hline \multirow[t]{2}{*}{ Variables } & \multicolumn{4}{|c|}{ Quarters of telomere length } & \multirow[b]{2}{*}{ P-trend } \\
\hline & $\overline{Q 1}$ & Q2 & Q3 & Q4 & \\
\hline $\bar{N}$ & 1068 & 1057 & 1068 & 1066 & \\
\hline$T L$, Mean $\pm S E M$ & $0.76 \pm 0.02$ & $0.95 \pm 0.01$ & $1.10 \pm 0.04$ & $1.41 \pm 0.10$ & \\
\hline a-carotene(umol/L) & $0.062 \pm .004$ & $0.080 \pm 002$ & $0.084 \pm 008$ & $0.087 \pm 003$ & $<0.001$ \\
\hline trans- $\beta$-carotene(umol/L) & $0.29 \pm .012$ & $0.35 \pm .01$ & $0.36 \pm .01$ & $0.38 \pm .01$ & $<0.001$ \\
\hline cis- $\beta$-carotene(umol/L) & $0.017 \pm .001$ & $0.020 \pm .001$ & $0.021 \pm .001$ & $022 \pm .001$ & $<0.001$ \\
\hline$\beta$-cryptoxanthin(umol/L) & $0.172 \pm .005$ & $0.197 \pm .005$ & $0.196 \pm .005$ & $0.195 \pm .005$ & $<0.001$ \\
\hline g-tocopherol(umol/L) (vitamins E) & $5.93 \pm .10$ & $5.75 \pm .10$ & $5.66 \pm .10$ & $5.30 \pm .10$ & $<0.001$ \\
\hline Combined Lutein/zeaxanthin(umol/L) & $0.270 \pm .005$ & $0.289 \pm .005$ & $0.295 \pm .005$ & $0.297 \pm .005$ & $<0.001$ \\
\hline trans-lycopene(umol/L) & $0.398 \pm .006$ & $0.411 \pm .006$ & $0.417 \pm .006$ & $0.417 \pm .006$ & $<0.001$ \\
\hline Retinyl palmitate(umol/L) & $0.085 \pm .003$ & $0.081 \pm .003$ & $0.086 \pm .003$ & $0.094 \pm .003$ & $<0.001$ \\
\hline Retinyl stearate(umol/L) & $0.018 \pm .001$ & $0.016 \pm .001$ & $0.017 \pm .001$ & $0.019 \pm .001$ & $<0.001$ \\
\hline Retinol(umol/L) (vitamins A) & $2.08 \pm .020$ & $2.09 \pm .018$ & $2.11 \pm .018$ & $2.11 \pm .018$ & $<0.001$ \\
\hline a -tocopherol(umol/L) (vitamins E) & $30.88 \pm .46$ & $31.39 \pm .43$ & $31.77 \pm .43$ & $31.12 \pm .45$ & $<0.001$ \\
\hline
\end{tabular}

$P$-values for linear trend across quartiles of telomere length. Variables were compared across quartiles of telomere length using analysis of co-variance (ANCOVA) test 
Table 2 Crude and multi-variable (age-sex-race-education-marital status-BMI-Smoking-CRP) association between telomere length and serum antioxidant

\begin{tabular}{|c|c|c|c|c|}
\hline \multirow[t]{2}{*}{ Variables } & \multicolumn{2}{|c|}{ Crude model } & \multicolumn{2}{|c|}{ Multivariable model } \\
\hline & $\bar{\beta}$ & $95 \% \mathrm{Cl}$ & $\bar{\beta}$ & $p$-value \\
\hline a-carotene(umol/L) & 0.021 & $(-0.019,0.113)$ & 0.058 & $\overline{(0.246,0.807)}$ \\
\hline trans- $\beta$-carotene(umol/L) & -0.026 & $(-0.037,0.003)$ & 0.060 & $(0.081,0.251)$ \\
\hline cis- $\beta$-carotene(umol/L) & -0.026 & $(-0.663,0.051)$ & 0.061 & $(1.52,4.59)$ \\
\hline$\beta$-cryptoxanthin(umol/L) & 0.041 & $(0.016,0.108)$ & 0.049 & $(0.112,0.501)$ \\
\hline g-tocopherol(umol/L) & -0.047 & $(-0.006,-0.001)$ & -0.016 & $(-0.062,0.126)$ \\
\hline Combined Lutein/zeaxanthin(umol/L) & -0.023 & $(-0.082,0.010)$ & 0.400 & $(0.062,0.495)$ \\
\hline trans-lycopene(umol/L) & 0.142 & $(0.132,0.203)$ & 0.017 & $(-0.066,0.238)$ \\
\hline Retinyl palmitate(umol/L) & -0.002 & $(-0.087,0.074)$ & 0.015 & $(-0.178,0.498)$ \\
\hline Retinyl stearate(umol/L) & -0.052 & $(-0.714,-0.187)$ & 0.004 & $(-0.959,1.261)$ \\
\hline Retinol(umol/L) & -0.035 & $(-0.062,0.040)$ & 0.006 & $(-0.039,0.058)$ \\
\hline a -tocopherol(umol/L) & -0.050 & $(-0.516,0.0129)$ & 0.008 & $(-0.002,0.003)$ \\
\hline
\end{tabular}

Linear regression, adjusted for age-sex-race-education-marital status-BMI-Smoking-CRP

that no other antioxidants (nor the pooled subgroups of provitamin A, non-provitamin A, vitamin E, and total antioxidant status of all micronutrients) were associated with TL. The authors proposed a protective role of these specific vitamins in telomere maintenance [25]. Further, the European Prospective Investigation into Cancer and Nutrition (EPIC) found that a higher consumption of vegetables was meaningfully associated with higher mean TL in peripheral lymphocytes. Particularly, $\beta$-carotene consumption significantly increased mean TL [35]. A recent study by Min, et al. from Japan reported for the first time a positive association between TL and daily intake of antioxidant vitamins, particularly among certain genotypes [31, 35]. Sen et al. investigated the association between plasma antioxidant levels and leukocyte telomere length in 786 elderly adults. A significant effect of combined lutein/zeaxanthin on longer telomeres was observed, whereas no other carotenoids were associated with telomere length [25].

Several potential mechanisms have been proposed for a positive association between antioxidant levels and TL $[25,36-38]$. It is consistent with our findings that antioxidants would maintain TL $[31,39]$. Oxidative stress is considered to be an important contributing factor for telomere shortening because of the high guanine content in telomeres. Oxidative stress is considered to be an important contributing factor for telomere shortening because of the high guanine content in telomeres. Guanine is highly sensitive to reactive oxygen species, resulting in the production of 8-oxo-7,8-dihydrodeoxyguanosine, which can lead to DNA strand breaks, resulting in telomeric attrition [1]. Antioxidant vitamins, including a-tocopherol, g-tocopherol, and carotenoids, may limit the effects of oxidative stress and possibly slow telomeric attrition. Several in vitro and in vivo studies have shown that lutein, zeaxanthin and vitamin $\mathrm{C}$ prevent DNA breakage and modulate DNA repair through their anti-oxidative activity [25, 36-38]. Moreover, previous clinical investigations proposed that non-pro-vitamin A carotenoids have greater protective effects against DNA damage than pro-vitamin A carotenoids [25, 36]. Other proposed mechanisms, particularly for the protective effect of lutein, zeaxanthin and vitamin $\mathrm{C}$, include effects on immune-modulation, anti-inflammatory activity, modulation of apoptosis, and lymphocyte proliferation [25, 40, 41]. Several investigations conducted on other dietary components, including $\mathrm{B}$ vitamins like folate [42-44] point to their role in DNA methylation and consequently regulation of TL by DNA methylation [43].

Even though we have adjusted our models for potential confounders, our results should be considered with caution as it has been reported higher serum antioxidant levels with higher intakes of vegetables and fruits, and also with higher socioeconomic status (SES) [45]. Therefore, the positive association between certain dietary antioxidants and TL may also be explained by a more healthy life style/higher SES. It should also be realized that oxidative stress as it occurs with chronic inflammation may cause consumption of certain serum antioxidants [46] as well as a reduction of $\mathrm{TL}$, thereby contributing to the association between certain antioxidants and TL. The cross-sectional nature of our study does not allow inferences about causality. Circulating levels of nutrients may be a marker for an overall healthier lifestyle. Although we accounted for several lifestyle factors, such as BMI, smoking, and physical activity level, it is possible that the inclusion of these covariates did not completely account for factors that may confound the associations between vitamins and TL. In the current study we just focused on Leucocytes TL, more studies on other TL are warranted. 
The strength of the study could be its large sample size and the high quality of the methods measuring antioxidants and TL. The NHANES is a large nationally representative sample of non-institutionalized adults with comprehensive biomarkers and health information. An additional strength is the use of objectively measured biomarkers in the analysis rather than relying on self-reported dietary intake.

\section{Conclusion}

In conclusion, results of the present study support the potential role of dietary antioxidants in preserving TL. This potential protective role of high antioxidant foods on TL has clinical implications with respect to biological aging and non-communicable disease. Further longitudinal studies are needed to confirm our findings, and to test whether changes in dietary antioxidants would preserve TL over time.

\section{Abbreviations \\ ANCOVA: Analysis of co-variance; ASPS: Austrian stroke prevention study; BMI: Body mass index; CDC: Centers for diseases control; CRP: C-reactive protein; EPIC: European Prospective Investigation into Cancer and Nutrition; NCHS: National Center for Health Statistics; NHANES: National health and nutrition examination survey; $\mathrm{TL}$ : Telomere length}

\section{Acknowledgments}

MM was supported by a TWAS studentship of the Chinese Academy of Sciences.

\section{Availability of data and materials}

All the data are from public access database.

\section{Authors' contributions}

MM: contributed to the study concept and design, data analysis and interpretation, and drafting of the manuscript and contributed to the critical revision of the manuscript. APK, CKJ: contributed to the data analysis and interpretation, and drafting of the manuscript. MB: contributed to the critical revision of the manuscript. All authors read and approved the final manuscript.

\section{Ethics approval and consent to participate}

For the data collection and physical examination of the NHANES, informed consent was obtained from all adult participants, and the National Centre for Health Statistics Research Ethics Review Board approved the protocol.

\section{Consent for publication}

For the data collection and physical examination of the NHANES, informed consent (publication) was obtained from all adult participants, and the National Centre for Health Statistics Research Ethics Review Board approved the protocol.

\section{Competing interests}

The corresponding author is responsible for submitting a competing financial interest statement on behalf of all authors of the paper. The authors declare that they have no competing financial interests.

\section{Publisher's Note}

Springer Nature remains neutral with regard to jurisdictional claims in published maps and institutional affiliations.

\section{Author details}

'Department of Biology and Biological Engineering, Food and Nutrition Science, Chalmers University of Technology, SE-412 96 Gothenburg, Sweden. ${ }^{2}$ Non-Communicable Disease Research Unit, South African Medical Research Council and University of Cape Town, Cape Town, South Africa. ${ }^{3}$ Department of Health, Johns Hopkins Weight Management Center Behavior and Society,
Johns Hopkins Bloomberg School of Public Health, Johns Hopkins University, Baltimore, MD, USA. ${ }^{4}$ Global Obesity Prevention Center at Johns Hopkins University, International Health/Human Nutrition, Johns Hopkins University Bloomberg School of Public Health, Baltimore, MD, USA. ${ }^{5}$ Department of Hypertension, Chair of Nephrology and Hypertension, Medical University of Lodz, Lodz, Poland. 'Polish Mother's Memorial Hospital Research Institute (PMMHRI), Lodz, Poland. ${ }^{7}$ Cardiovascular Research Center, University of Zielona-Gora, Zielona Gora, Poland.

Received: 13 October 2017 Accepted: 15 May 2018 Published online: 20 July 2018

\section{References}

1. Blackburn EH. Structure and function of telomeres. Nature. 1991;350(6319): 569-73.

2. Sanders JL, Newman AB. Telomere length in epidemiology: a biomarker of aging, age-related disease, both, or neither? Epidemiol Rev. 2013;35:112-31.

3. Kurz DJ, Decary S, Hong Y, Trivier E, Akhmedov A, Erusalimsky JD. Chronic oxidative stress compromises telomere integrity and accelerates the onset of senescence in human endothelial cells. J Cell Sci. 2004:117(11):2417-26.

4. Cherkas LF, Hunkin JL, Kato BS, Richards JB, Gardner JP, Surdulescu GL, et al. The association between physical activity in leisure time and leukocyte telomere length. Arch Intern Med. 2008;168(2):154-8.

5. Codd V, Nelson CP, Albrecht E, Mangino M, Deelen J, Buxton JL, et al. Identification of seven loci affecting mean telomere length and their association with disease. Nat Genet. 2013;45(4):422-7.

6. Crous-Bou M, Fung TT, Prescott J, Julin B, Du M, Sun Q, et al. Mediterranean diet and telomere length in nurses' health study: population based cohort study. BMJ (Clinical research ed). 2014;349:g6674.

7. Valdes AM, Andrew T, Gardner JP, Kimura M, Oelsner E, Cherkas LF, et al. Obesity, cigarette smoking, and telomere length in women. Lancet. 2005;366(9486):662-4.

8. Aviv A. Telomeres and human aging: facts and fibs. Science's SAGE KE. 2004;2004(51):pe43.

9. Frenck RW, Blackburn EH, Shannon KM. The rate of telomere sequence loss in human leukocytes varies with age. Proc Natl Acad Sci. 1998;95(10):5607-10.

10. Fitzpatrick AL, Kronmal RA, Gardner JP, Psaty BM, Jenny NS, Tracy RP, et al Leukocyte telomere length and cardiovascular disease in the cardiovascular health study. Am J Epidemiol. 2007:165(1):14-21.

11. O'Donnell CJ, Demissie S, Kimura M, Levy D, Gardner JP, White C, et al. Leukocyte telomere length and carotid artery intimal medial thickness the Framingham heart study. Arterioscler Thromb Vasc Biol. 2008;28(6):1165-71.

12. Demissie S, Levy D, Benjamin EJ, Cupples LA, Gardner JP, Herbert A, et al. Insulin resistance, oxidative stress, hypertension, and leukocyte telomere length in men from the Framingham heart study. Aging Cell. 2006;5(4):325-30.

13. Salpea KD, Talmud PJ, Cooper JA, Maubaret CG, Stephens JW, Abelak K, et al. Association of telomere length with type 2 diabetes, oxidative stress and UCP2 gene variation. Atherosclerosis. 2010;209(1):42-50.

14. Vasan RS, Demissie S, Kimura M, Cupples LA, Rifai N, White C, et al. Association of Leukocyte Telomere Length with Circulating Biomarkers of the renin-angiotensin-aldosterone system the Framingham heart study. Circulation. 2008;117(9):1138-44

15. Mazidi M, Kengne AP, Sahebkar A, Banach M. Telomere length is associated with Cardiometabolic factors in US adults. Angiology. 2018:69(2):164-169. https://doi.org/10.1177/0003319717712860. Epub 2017 Jun 6.

16. Jang JS, Choi YY, Lee WK, Choi JE, Cha SI, Kim YJ, et al. Telomere length and the risk of lung cancer. Cancer Sci. 2008;99(7):1385-9.

17. Cawthon RM, Smith KR, O'Brien E, Sivatchenko A, Kerber RA. Association between telomere length in blood and mortality in people aged 60 years or older. Lancet. 2003:361(9355):393-5.

18. Epel ES, Blackburn EH, Lin J, Dhabhar FS, Adler NE, Morrow JD, et al. Accelerated telomere shortening in response to life stress. Proc Natl Acad Sci U S A. 2004:101(49):17312-5.

19. von Zglinicki T. Oxidative stress shortens telomeres. Trends Biochem Sci. 2002:27(7):339-44

20. Farzaneh-Far R, Lin J, Epel ES, Harris WS, Blackburn EH, Whooley MA. Association of marine omega-3 fatty acid levels with telomeric aging in patients with coronary heart disease. JAMA. 2010;303(3):250-7.

21. Chen L, Stacewicz-Sapuntzakis M, Duncan C, Sharifi R, Ghosh L, Van Breemen $R$, et al. Oxidative DNA damage in prostate cancer patients 
consuming tomato sauce-based entrees as a whole-food intervention. J Natl Cancer Inst. 2001;93(24):1872-9.

22. Uttara B, Singh AV, Zamboni P, Mahajan RT. Oxidative stress and neurodegenerative diseases: a review of upstream and downstream antioxidant therapeutic options. Curr Neuropharmacol. 2009;7(1):65-74.

23. Cassidy A, De Vivo I, Liu Y, Han J, Prescott J, Hunter DJ, et al. Associations between diet, lifestyle factors, and telomere length in women. Am J Clin Nutr. 2010;91(5):1273-80

24. Xu Q, Parks CG, DeRoo LA, Cawthon RM, Sandler DP, Chen H. Multivitamin use and telomere length in women. Am J Clin Nutr. 2009;89(6):1857-63.

25. Sen A, Marsche G, Freudenberger P, Schallert M, Toeglhofer AM, Nagl C, et al. Association between higher plasma lutein, zeaxanthin, and vitamin $C$ concentrations and longer telomere length: results of the Austrian stroke prevention study. J Am Geriatr Soc. 2014;62(2):222-9.

26. Klein-Platat C, Drai J, Oujaa M, Schlienger JL, Simon C. Plasma fatty acid composition is associated with the metabolic syndrome and low-grade inflammation in overweight adolescents. Am J Clin Nutr. 2005;82(6): $1178-84$.

27. Mazidi M, Kengne AP, Vatanparast $\mathrm{H}$. Association of dietary patterns of American adults with bone mineral density and fracture. Public Health Nutr. 2018:1-7. https://doi.org/10.1017/S1368980018000939. [Epub ahead of print]

28. Needham BL, Adler N, Gregorich S, Rehkopf D, Lin J, Blackburn EH, et al. Socioeconomic status, health behavior, and leukocyte telomere length in the National Health and nutrition examination survey, 1999-2002. Soc Sci Med. 2013;85:1-8.

29. EDM MM, Banach M. The association of telomere length and serum 25hydroxyvitamin D levels in US adults: the National Health and nutrition examination survey. Arch Med Sci. 2017;13(1):61-5

30. Mazidi M, Mikhailidis DP, Banach M. Higher dietary acid load is associated with higher likelihood of peripheral arterial disease among American adults. J Diabetes Complications. 2018;32(6):565-569. https://doi.org/10.1016/j. jdiacomp.2018.03.001. Epub 2018 Mar 9.

31. Min KB, Min JY. Association between leukocyte telomere length and serum carotenoid in US adults. Eur J Nutr. 2017;56(3):1045-1052. https://doi.org/10. 1007/s00394-016-1152-x. Epub 2016 Jan 27.

32. McGrane MM. Vitamin a regulation of gene expression: molecular mechanism of a prototype gene. J Nutr Biochem. 2007;18(8):497-508.

33. Stephensen CB, Vitamin A. Infection, and immune function. Annu Rev Nutr. 2001:21:167-92

34. Krinsky NI, Johnson EJ. Carotenoid actions and their relation to health and disease. Mol Asp Med. 2005;26(6):459-516

35. Marcon F, Siniscalchi E, Crebelli R, Saieva C, Sera F, Fortini P, et al. Dietrelated telomere shortening and chromosome stability. Mutagenesis. 2012;27(1):49-57.

36. Azqueta A, Collins AR. Carotenoids and DNA damage. Mutation Res/ Fundam Mol Mech Mutagenesis. 2012;733(1):4-13.

37. Cooke MS, Evans MD, Podmore ID, Herbert KE, Mistry N, Mistry P, et al. Novel repair action of vitamin $C$ upon in vivo oxidative DNA damage. FEBS Lett. 1998:439(3):363-7.

38. Santocono M, Zurria M, Berrettini M, Fedeli D, Falcioni G. Lutein, zeaxanthin and astaxanthin protect against DNA damage in SK-N-SH human neuroblastoma cells induced by reactive nitrogen species. J Photochem Photobiol B Biol. 2007;88(1):1-10.

39. Kim SY, Velando A. Antioxidants safeguard telomeres in bold chicks. Biol Lett. 2015;11(5):20150211.

40. Härtel C, Puzik A, Göpel W, Temming P, Bucsky P, Schultz C. Immunomodulatory effect of vitamin C on intracytoplasmic cytokine production in neonatal cord blood cells. Neonatology. 2006;91(1):54-60.

41. Wannamethee SG, Lowe GD, Rumley A, Bruckdorfer KR, Whincup PH Associations of vitamin C status, fruit and vegetable intakes, and markers of inflammation and hemostasis. Am J Clin Nutr. 2006;83(3): 567-74.

42. Bull C, Christensen $\mathrm{H}$, Fenech M. Cortisol is not associated with telomere shortening or chromosomal instability in human lymphocytes cultured under low and high folate conditions. PLoS One. 2015;10(3):e0119367.

43. Pusceddu I, Herrmann M, Kirsch SH, Werner C, Hübner U, Bodis M et al. Prospective study of telomere length and LINE-1 methylation in peripheral blood cells: the role of B vitamins supplementation. Eur J Nutr. 2016;55(5):1863-73. https://doi.org/10.1007/s00394-015-1003-1. Epub 2015 Aug 21.
44. Shin C, Baik I. Leukocyte telomere length is associated with serum vitamin B12 and homocysteine levels in older adults with the presence of systemic inflammation. Clinical nutrition research. 2016;5(1):7-14

45. Duthie SJ, Duthie GG, Russell WR, Kyle JAM, Macdiarmid JI, Rungapamestry $V$, et al. Effect of increasing fruit and vegetable intake by dietary intervention on nutritional biomarkers and attitudes to dietary change: a randomised trial. In: Eur J Nutr; 2017. https://doi.org/ 10.1007/s00394-017-1469-0.

46. Rubin LP, Ross AC, Stephensen CB, Bohn T, Tanumihardjo SA. Metabolic effects of inflammation on vitamin a and carotenoids in humans and animal models. Adv Nutr. 2017:8(2):197-212. https://doi.org/10.3945/an.116. 014167. Print 2017 Mar.

\section{Ready to submit your research? Choose BMC and benefit from:}

- fast, convenient online submission

- thorough peer review by experienced researchers in your field

- rapid publication on acceptance

- support for research data, including large and complex data types

- gold Open Access which fosters wider collaboration and increased citations

- maximum visibility for your research: over $100 \mathrm{M}$ website views per year

At BMC, research is always in progress.

Learn more biomedcentral.com/submissions 